\title{
Effect of $\mathrm{Al}$ content on microstructure of Ti-Al-Nb-C-Mo composites reinforced with carbide particles
}

\author{
A. Klimová*, J. Lapin \\ Institute of Materials and Machine Mechanics, Slovak Academy of Sciences, \\ Dúbravská cesta 9, 84513 Bratislava 3, Slovak Republic
}

Received 3 October 2019, received in revised form 4 November 2019, accepted 5 November 2019

\begin{abstract}
The effect of $\mathrm{Al}$ content on the microstructure of $\mathrm{Ti}-x \mathrm{Al}-8 \mathrm{Nb}-3.6 \mathrm{C}-0.8 \mathrm{Mo}$ (at.\%) composites reinforced with carbide particles, where $x=38,42,45$, and 47 at.\%, was studied. The composites prepared by vacuum induction melting in graphite crucibles followed by centrifugal casting into graphite moulds were studied in the as-cast and heat-treated state. The intermetallic matrices of the as-cast composites consisting of $\alpha_{2}\left(\mathrm{Ti}_{3} \mathrm{Al}\right)-, \gamma(\mathrm{TiAl})-$, and $\beta / \mathrm{B} 2(\mathrm{Ti})$-phases are reinforced with uniformly distributed carbide particles composed of $(\mathrm{Ti}, \mathrm{Nb})_{2} \mathrm{AlC}$-phase and small amount of $(\mathrm{Ti}, \mathrm{Nb}) \mathrm{C}$-phase preserved in the cores of some coarse irregular shaped carbides. The increasing $\mathrm{Al}$ content leads to a decrease in the volume fraction of $\beta / \mathrm{B} 2$-phase and an increase in the volume fraction of the lamellar $\alpha_{2}+\gamma$ and single $\gamma$-phase regions in the as-cast composites. The increasing $\mathrm{Al}$ content increases shape factor and decreases the mean size of the primary carbide particles. In the heat-treated composites, the intermetallic matrices change from multiphase composed of lamellar $\alpha_{2}+\gamma$ grains with $\beta /$ B2-and $\gamma$-phase regions formed along the lamellar grain boundaries, through nearly lamellar to single $\gamma$-phase with increasing $\mathrm{Al}$ content. The $(\mathrm{Ti}, \mathrm{Nb}) \mathrm{C}$ regions in the core of some carbide particles transform to $(\mathrm{Ti}, \mathrm{Nb})_{2} \mathrm{AlC}$-phase during the heat-treatment. The Vickers hardness and matrix microhardness decrease with the increasing $\mathrm{Al}$ content in both the as-cast and heat-treated composites.

Key words: intermetallics, TiAl, composites, casting, microstructure, hardness
\end{abstract}

\section{Introduction}

TiAl-based alloys provide a unique set of physical and mechanical properties for high-temperature structural applications in turbochargers, automotive combustion engines, and aircraft engines [1-5]. Depending on their chemical composition and processing parameters, these alloys can be produced with four different types of microstructure: near-gamma (NG), duplex (DP), near lamellar (NL), and fully lamellar (FL) [6-9]. The DP/NG alloys are characterised by higher room temperature (RT), tensile strength, ductility, and longer fatigue life than FL/NL ones [6]. On the other hand, the FL/NL alloys exhibit better creep resistance, higher fracture toughness, and crack propagation resistance than DP/NG structures $[7,8]$. However, insufficient strength of TiAl-based alloys with various microstructures at high temperatures (above $\left.800^{\circ} \mathrm{C}\right)$ limit their wide-scale applications $[6,10,11]$. Intermetallic matrix composites may improve this deficiency at high temperatures due to a good combination of the properties of the intermetallic matrix and reinforcement. Among various ceramics used as the reinforcements, $\mathrm{Ti}_{2} \mathrm{AlC}$ as a layered ternary MAX-phase ( $\mathrm{M}$ is a transition metal, $\mathrm{A}$ is an A-group element, and $\mathrm{X}$ is carbon) shows a significant role in toughening and reinforcing of TiAl-based matrix composites. The unique combination of both metallic and ceramic properties of $\mathrm{Ti}_{2} \mathrm{AlC}$, such as high fracture resistance, excellent damage tolerance, good thermal and electrical conductivity, easy machinability, good thermal shock and oxidation resistance, high elastic modulus and thermochemical stability benefit fabrication of insitu composites [12-16]. Besides the coarse primary $\mathrm{Ti}_{2} \mathrm{AlC}$ particles, the additional strengthening of the in-situ composites can be achieved by fine secondary

*Corresponding author: tel.: +421 23240 1055; e-mail address: alena.klimova@savba.sk 
needle-like perovskite $\mathrm{P}-\mathrm{Ti}_{3} \mathrm{AlC}$ and plate-like hexagonal $\mathrm{H}-\mathrm{Ti}_{2} \mathrm{AlC}$ precipitates forming in the TiAl matrix and along grain boundaries as has been observed in several carbon-containing TiAl-based alloys [17-20].

Various techniques including powder metallurgy, mechanical alloying, reactive hot pressing, spark plasma sintering, vacuum induction melting, vacuum arc remelting, and combustion synthesis have been investigated for processing of in-situ TiAl matrix composites reinforced with $\mathrm{Ti}_{2} \mathrm{AlC}$ particles [12-14, 2126]. Among these techniques, vacuum induction melting and precise casting are of large industrial interest for the production of complex-shaped components such as turbocharger wheels, exhaust valves, or turbine blades in a cost-effective way [3-5]. Melting crucibles showing the highest thermochemical stability against TiAl melts such as $\mathrm{ZrO}_{2}$ and $\mathrm{Y}_{2} \mathrm{O}_{3}$ are expensive, and $\mathrm{CaO}$ is sensitive to the humidity [2730]. As was reported by several authors [13, 31, 32], an increase of carbon content during vacuum induction melting in relatively cheap graphite crucibles can be successfully controlled by processing parameters. Hence, it is of large interest to apply vacuum induction melting in graphite crucibles for processing of TiAl-based matrix composites reinforced with carbide particles.

This paper aims to study the effect of $\mathrm{Al}$ content on the microstructure of centrifugally cast $\mathrm{Ti}-x \mathrm{Al}-8 \mathrm{Nb}-$ -3.6C-0.8Mo (at.\%) composites reinforced with carbide particles, where $x=38,42,45$, and 47 at. $\%$. Also, the effect of heat treatment consisting of solution annealing and cooling at a constant rate on the microstructure and redistribution of alloying elements is reported and discussed. The variation in the $\mathrm{Al}$ content aims at achieving microstructurally different types of intermetallic matrices such as $\gamma(\mathrm{TiAl})$, multiphase with a high amount of lamellar $\alpha_{2}\left(\mathrm{Ti}_{3} \mathrm{Al}\right)+$ $\gamma$ regions and lamellar $\alpha_{2}+\gamma$. The $\gamma$ matrix is expected to improve room temperature tensile strength, room temperature ductility, and fatigue life of the composites compared to those of the composites with multiphase or lamellar matrices. On the other hand, improved high temperature creep resistance, higher fracture toughness and crack propagation resistance is expected for the composites with a lamellar matrix, which would make these materials interesting for structural applications beyond $800^{\circ} \mathrm{C}$.

\section{Experimental material and procedures}

The composites with nominal composition Ti- $x \mathrm{Al}-$ -8Nb-3.6C-0.8Mo (at.\%), where $x=38,42,45$, and 47 at.\%, were prepared by vacuum induction melting in graphite crucibles with an inner diameter of $45 \mathrm{~mm}$ and length of $75 \mathrm{~mm}$. The vacuum chamber of the induction melting furnace was evacuated to a vacuum pressure of $4.5 \mathrm{~Pa}$ and flushed with argon three times. After increasing the vacuum pressure to $10^{3} \mathrm{~Pa}$ by a partial filling with argon (purity of $99.9995 \%$ ), the charge was heated to a melt temperature of $1650^{\circ} \mathrm{C}$ and hold at this temperature for $30 \mathrm{~s}$. The temperature of the melt was measured by a pyrometer. The melt was centrifugally cast into a cold graphite mould at a rotation speed of $250 \mathrm{rpm}$ under a vacuum pressure of $10^{3} \mathrm{~Pa}$. The centrifugally cast conical samples with a minimum diameter of $12 \mathrm{~mm}$, the maximum diameter of $14 \mathrm{~mm}$, and length of $150 \mathrm{~mm}$ were removed from the mould and cut to smaller pieces with a length of $20 \mathrm{~mm}$ for heat treatments and metallographic observations.

The composites were subjected to heat treatment consisting of heating to a solution annealing temperature of $1420^{\circ} \mathrm{C}$ at a heating rate of $10^{\circ} \mathrm{C} \mathrm{min}{ }^{-1}$, holding at this temperature for $1 \mathrm{~h}$, cooling to a temperature of $700{ }^{\circ} \mathrm{C}$ at a rate of $5^{\circ} \mathrm{C} \mathrm{min}-1$, and furnace cooling to room temperature under argon atmosphere. The temperature of the samples was continuously monitored by the Pt-PtRh10 thermocouple touching the sample surface. The acquisition of timetemperature data was performed electronically using the acquisition module and computer.

Standard metallographic techniques such as grinding on $\mathrm{SiC}$ papers, polishing on diamond paste with various grain sizes ranging from 10 to $0.25 \mu \mathrm{m}$, and etching in a solution of $100 \mathrm{ml} \mathrm{H} \mathrm{H}_{2} \mathrm{O}, 6 \mathrm{ml} \mathrm{HNO}_{3}$, and $3 \mathrm{ml} \mathrm{HF}$ were used. Microstructure investigations were performed by optical microscopy (OM), scanning electron microscopy (SEM), scanning electron microscopy in backscattered electron (BSE) mode, and X-ray diffraction analysis (XRD). X-ray diffraction (XRD) analysis was carried out by a diffractometer equipped with an X-ray tube with rotating $\mathrm{Cu}$ anode operating at $12 \mathrm{~kW}$. Chemical composition of the in-situ composites was analysed by energy-dispersive spectrometry (EDS) calibrated using the standards for measurements of the composition of carbides ( $\mathrm{TiC}$, $\mathrm{Ti}_{2} \mathrm{AlC}$ ). The average content of carbon in the samples was measured by LECO CS844 elemental analyser. Oxygen and nitrogen contents were measured by a LECO ONH836 elemental analyser. Size, morphology, and volume fraction of the coexisting phases were determined from the digitalised micrographs using computer image analyser and measured data were treated by statistical methods.

Vickers hardness measurements were performed by a universal hardness testing machine. Vickers hardness tests were carried out at an applied load of $298 \mathrm{~N}$, holding time at the point of load application of $2 \mathrm{~s}$ and rate of load application of $15 \mathrm{~N} \mathrm{~s}^{-1}$ on the as-cast and heat-treated samples. Vickers microhardness measurements of the matrix of the composite were performed by a microhardness tester. The measurements were performed at an applied load of $0.98 \mathrm{~N}$ and dwell time 
Ta ble 1. Chemical composition of the composites

\begin{tabular}{|c|c|c|c|c|c|c|c|}
\hline \multirow{2}{*}{ Composite } & \multicolumn{5}{|c|}{ Element (at.\%) } & \multicolumn{2}{|c|}{ Element (wt.ppm) } \\
\hline & $\mathrm{Ti}$ & $\mathrm{Al}$ & $\mathrm{Nb}$ & Mo & $\mathrm{C}$ & $\mathrm{O}$ & $\mathrm{N}$ \\
\hline $38 \mathrm{Al}$ & $49.3 \pm 0.3$ & $38.1 \pm 0.4$ & $8.0 \pm 0.1$ & $0.8 \pm 0.1$ & $3.8 \pm 0.1$ & $866 \pm 46$ & $339 \pm 38$ \\
\hline $42 \mathrm{Al}$ & $45.3 \pm 0.4$ & $42.1 \pm 0.3$ & $8.1 \pm 0.1$ & $0.8 \pm 0.1$ & $3.7 \pm 0.1$ & $835 \pm 41$ & $390 \pm 42$ \\
\hline $45 \mathrm{Al}$ & $42.6 \pm 0.1$ & $45.0 \pm 0.4$ & $7.9 \pm 0.1$ & $0.7 \pm 0.1$ & $3.8 \pm 0.1$ & $874 \pm 47$ & $398 \pm 46$ \\
\hline $47 \mathrm{Al}$ & $40.6 \pm 0.2$ & $47.2 \pm 0.2$ & $7.9 \pm 0.1$ & $0.7 \pm 0.1$ & $3.6 \pm 0.1$ & $885 \pm 49$ & $375 \pm 40$ \\
\hline
\end{tabular}
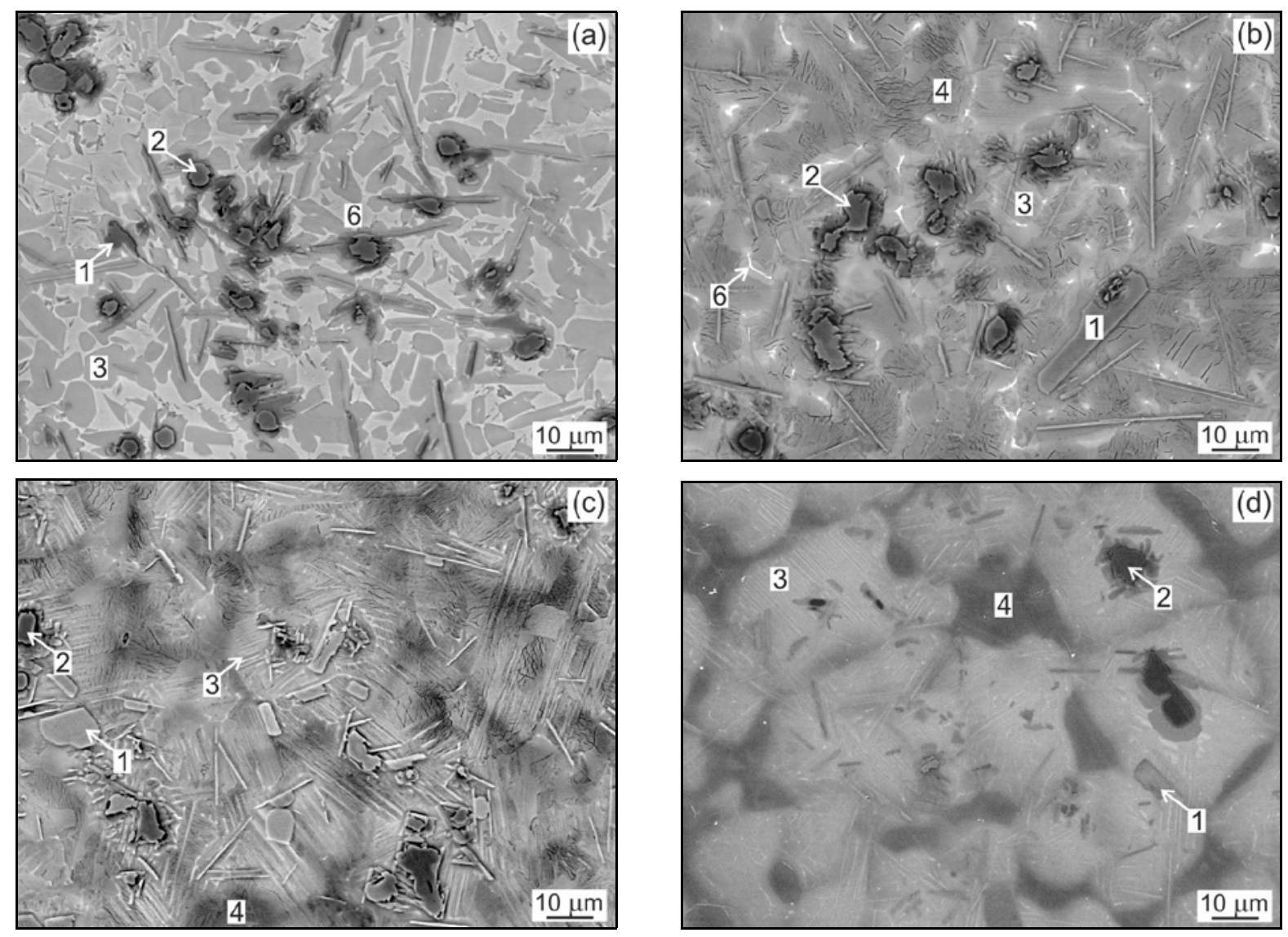

Fig. 1. The microstructure of the as-cast composites, BSE: (a) 38Al, (b) 42Al, (c) 45Al, and (d) 47Al. The chemical composition of analysed regions marked in the figures is summarised in Table 2.

of $10 \mathrm{~s}$ on polished and slightly etched sections of the centrifugally cast and heat-treated samples. Instrumented nanoindentation measurements of coexisting phases were carried out at an applied load of $0.01 \mathrm{~N}$ and holding time at the point of load application of $2 \mathrm{~s}$ on polished and slightly etched samples using a nanoindenter with Berkovich tip of the indenter.

\section{Results}

\subsection{Chemical composition}

The average chemical composition of the studied composites designated as $38 \mathrm{Al}, 42 \mathrm{Al}, 45 \mathrm{Al}$, and $47 \mathrm{Al}$ is summarised in Table 1 . The content of $\mathrm{Al}$ in the ingots is in accordance with the designed nominal compositions $\mathrm{Ti}-x \mathrm{Al}-8 \mathrm{Nb}-3.6 \mathrm{C}-0.8 \mathrm{Mo}-0 . \mathrm{B}$ (at.\%), where $x=$ $38,42,45$, and 47 at. $\%$. The content of the other alloying elements ( $\mathrm{Nb}, \mathrm{Mo}, \mathrm{C})$ in the studied composites varies only within the experimental error of the measurements. As has been shown in recent works [31, 33 , vacuum pressure ranging from $10^{3}$ to $10^{4} \mathrm{~Pa}$ has no significant effect on the content of the alloying elements, especially the content of $\mathrm{Al}$, which is susceptible to evaporation. The measured contents of oxygen and nitrogen in all studied composites do not exceed 900 wt.ppm and 400 wt.ppm, respectively. 


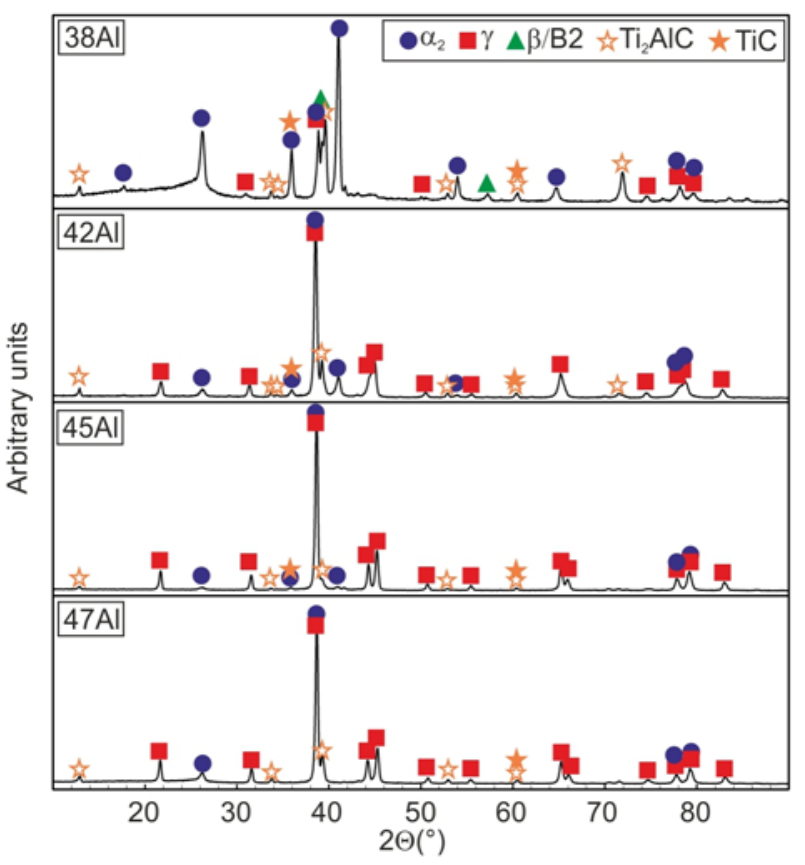

Fig. 2. The typical XRD patterns of the as-cast composites. The identified coexisting phases are indicated in the figure.

\subsection{Microstructure}

\subsubsection{The microstructure of as-cast composites}

The microstructure of the as-cast composites is formed by multiphase intermetallic matrices reinforced with relatively homogeneously distributed carbide particles, as seen in Fig. 1. The matrices of the composites consist of three phases: $\alpha_{2}\left(\mathrm{Ti}_{3} \mathrm{Al}\right)$, $\gamma(\mathrm{TiAl})$, and $\beta / \mathrm{B} 2(\mathrm{Ti})$, as is indicated by the XRD patterns in Fig. 2. The matrix of the $38 \mathrm{Al}$ composite is formed mainly by the $\alpha_{2}+\gamma$ and $\beta / \mathrm{B} 2$-phase regions (Fig. 1a). The matrix of the $42 \mathrm{Al}, 45 \mathrm{Al}$, and $47 \mathrm{Al}$ composites consists of $\gamma$ - and $\alpha_{2}$-phases and low volume fraction of $\beta /$ B2-phase, as seen in Figs. 1b-d. The matrix of the $42 \mathrm{Al}$ composite is formed predominantly by single $\gamma$ and $\alpha_{2}+\gamma$ regions (Fig. 1b). The pseudoduplex matrices of both the $45 \mathrm{Al}$ and $47 \mathrm{Al}$ composites are composed of lamellar $\gamma+\alpha_{2}$ colonies and large interdendritic $\gamma$-phase regions, as seen in Figs. 1c,d.

The measured chemical compositions of the lamellar $\alpha_{2}+\gamma$ (region 3), single-phase $\gamma$ (region 4), $\alpha_{2}$ (region 5) and $\beta / \mathrm{B} 2$ (region 6) (see Fig. 1) are summarised in Table 2 . The $\beta / \mathrm{B} 2$-phase regions are enriched by $\mathrm{Nb}$ and Mo. These two elements act as strong stabilisers of the $\beta$-phase, which modify significantly binary $\mathrm{Ti}-\mathrm{Al}$ phase diagram and tend to partition into $\beta$-phase rather than into the $\alpha$ - (Ti-based solid solution), $\alpha_{2}$ - or $\gamma$-phases [34]. As shown by XRD in Fig. 2 and EDS analysis in Table 2, the primary car-
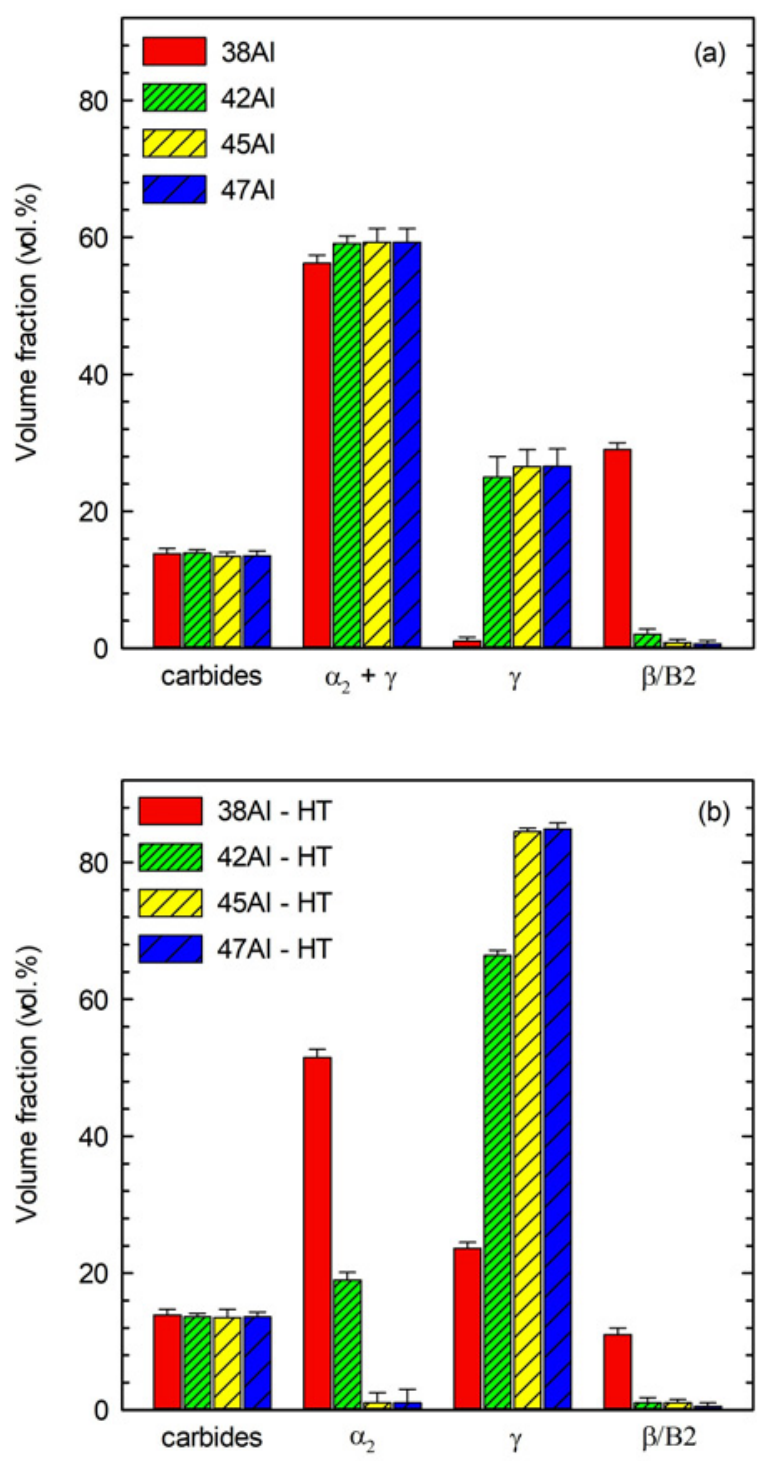

Fig. 3. (a) Volume fraction of primary carbide particles, lamellar $\alpha_{2}+\gamma$ colonies and $\beta / \mathrm{B} 2$ regions in the as-cast composites; (b) Volume fraction of primary carbide particles, $\alpha_{2}, \gamma$, and $\beta / \mathrm{B} 2$ regions in the heat-treated composites. The $\mathrm{Al}$ content in the composites is indicated in the figure.

bide particles belong to hexagonal ( $h P 8)$ type MAX-phase $(\mathrm{Ti}, \mathrm{Nb})_{2} \mathrm{AlC}$. In the cores of some coarse irregular shaped $(\mathrm{Ti}, \mathrm{Nb})_{2} \mathrm{AlC}$ particles, small regions of (Ti,Nb)C-phase with fcc $(c F 8)$ crystal structure are observed (region 2 in Fig. 1). The solubility of $\mathrm{Nb}$ in $(\mathrm{Ti}, \mathrm{Nb})_{2} \mathrm{AlC}$-phase reaches $(0.78 \pm 0.06)$ of the average $\mathrm{Nb}$ content measured in the composites. The $\mathrm{Al}$ content in the composite ranging from 38 to 47 at.\% has no significant effect on the solubility of $\mathrm{Nb}$ in the carbide particles. The similar tendency of lower content of $\mathrm{Nb}$ in MAX-phase particles compared to average content in the composites with 8 at.\% of $\mathrm{Nb}$ was 
Table 2. Chemical composition of coexisting microstructural regions measured by EDS in the as-cast and heat-treated composites

\begin{tabular}{|c|c|c|c|c|c|c|c|}
\hline \multirow{2}{*}{ Sample } & \multirow{2}{*}{ Region } & \multirow{2}{*}{$\begin{array}{c}\text { Phase } \\
\text { composition }\end{array}$} & \multicolumn{5}{|c|}{ Element (at.\%) } \\
\hline & & & $\mathrm{Ti}$ & $\mathrm{Al}$ & $\mathrm{Nb}$ & Mo & $\mathrm{C}$ \\
\hline \multirow{4}{*}{$38 \mathrm{Al}$} & 1 & $(\mathrm{Ti}, \mathrm{Nb})_{2} \mathrm{AlC}$ & $42.7 \pm 3.3$ & $24.9 \pm 2.6$ & $6.0 \pm 0.4$ & - & $26.4 \pm 0.7$ \\
\hline & 2 & $(\mathrm{Ti}, \mathrm{Nb}) \mathrm{C}$ & $46.5 \pm 2.0$ & $0.8 \pm 0.2$ & $5.4 \pm 1.0$ & - & $47.3 \pm 1.0$ \\
\hline & 3 & $\alpha_{2}+\gamma$ & $49.2 \pm 0.6$ & $41.9 \pm 0.5$ & $8.0 \pm 0.5$ & $0.9 \pm 0.2$ & - \\
\hline & 6 & $\beta / \mathrm{B} 2$ & $50.5 \pm 0.7$ & $39.3 \pm 0.7$ & $8.9 \pm 0.2$ & $1.3 \pm 0.1$ & - \\
\hline \multirow{5}{*}{ 38Al-HT } & 1 & $(\mathrm{Ti}, \mathrm{Nb})_{2} \mathrm{AlC}$ & $44.9 \pm 0.3$ & $24.6 \pm 0.3$ & $5.1 \pm 0.1$ & - & $25.5 \pm 0.5$ \\
\hline & 3 & $\alpha_{2}+\gamma$ & $50.5 \pm 0.2$ & $40.7 \pm 0.5$ & $8.0 \pm 0.2$ & $0.7 \pm 0.1$ & - \\
\hline & 4 & $\gamma$ & $46.4 \pm 1.2$ & $44.4 \pm 1.1$ & $8.5 \pm 0.1$ & $0.7 \pm 0.1$ & - \\
\hline & 5 & $\alpha_{2}$ & $51.9 \pm 0.4$ & $38.9 \pm 0.3$ & $8.3 \pm 0.1$ & $0.9 \pm 0.1$ & - \\
\hline & 6 & $\beta / \mathrm{B} 2$ & $51.8 \pm 1.2$ & $35.4 \pm 1.2$ & $10.1 \pm 0.6$ & $2.7 \pm 0.5$ & - \\
\hline \multirow{5}{*}{$42 \mathrm{Al}$} & 1 & $(\mathrm{Ti}, \mathrm{Nb})_{2} \mathrm{AlC}$ & $40.4 \pm 3.4$ & $25.3 \pm 3.8$ & $6.8 \pm 0.4$ & - & $27.5 \pm 1.9$ \\
\hline & 2 & $(\mathrm{Ti}, \mathrm{Nb}) \mathrm{C}$ & $40.6 \pm 3.3$ & $3.8 \pm 3.7$ & $6.5 \pm 0.3$ & - & $49.1 \pm 1.0$ \\
\hline & 3 & $\alpha_{2}+\gamma$ & $45.5 \pm 0.1$ & $45.3 \pm 0.3$ & $8.4 \pm 0.2$ & $0.8 \pm 0.1$ & - \\
\hline & 4 & $\gamma$ & $45.4 \pm 0.3$ & $45.1 \pm 0.5$ & $8.7 \pm 0.3$ & $0.8 \pm 0.1$ & - \\
\hline & 6 & $\beta / \mathrm{B} 2$ & $45.9 \pm 0.4$ & $41.3 \pm 1.2$ & $10.7 \pm 0.4$ & $2.1 \pm 0.5$ & - \\
\hline \multirow{5}{*}{$42 \mathrm{Al}-\mathrm{HT}$} & 1 & $(\mathrm{Ti}, \mathrm{Nb})_{2} \mathrm{AlC}$ & $41.0 \pm 1.5$ & $24.7 \pm 1.6$ & $5.9 \pm 0.1$ & - & $28.3 \pm 1.5$ \\
\hline & 3 & $\alpha_{2}+\gamma$ & $46.3 \pm 0.2$ & $44.0 \pm 0.2$ & $8.9 \pm 0.1$ & $0.9 \pm 0.1$ & - \\
\hline & 4 & $\gamma$ & $44.1 \pm 0.4$ & $46.3 \pm 0.5$ & $8.8 \pm 0.1$ & $0.8 \pm 0.1$ & - \\
\hline & 5 & $\alpha_{2}$ & $51.9 \pm 0.7$ & $37.9 \pm 0.7$ & $9.2 \pm 0.2$ & $1.0 \pm 0.1$ & - \\
\hline & 6 & $\beta / \mathrm{B} 2$ & $47.7 \pm 0.4$ & $38.5 \pm 0.2$ & $9.8 \pm 0.3$ & $4.1 \pm 0.1$ & - \\
\hline \multirow{4}{*}{$45 \mathrm{Al}$} & 1 & $(\mathrm{Ti}, \mathrm{Nb})_{2} \mathrm{AlC}$ & $41.0 \pm 1.7$ & $24.7 \pm 0.9$ & $6.6 \pm 0.5$ & - & $27.7 \pm 1.5$ \\
\hline & 2 & $(\mathrm{Ti}, \mathrm{Nb}) \mathrm{C}$ & $43.3 \pm 2.9$ & $1.7 \pm 1.4$ & $6.2 \pm 1.0$ & - & $48.8 \pm 1.2$ \\
\hline & 3 & $\gamma+\alpha_{2}$ & $43.6 \pm 0.4$ & $47.3 \pm 0.5$ & $8.4 \pm 0.3$ & $0.7 \pm 0.1$ & - \\
\hline & 4 & $\gamma$ & $42.5 \pm 0.5$ & $49.3 \pm 1.2$ & $7.4 \pm 0.9$ & $0.8 \pm 0.1$ & - \\
\hline \multirow{2}{*}{ 45Al-HT } & 1 & $(\mathrm{Ti}, \mathrm{Nb})_{2} \mathrm{AlC}$ & $43.0 \pm 0.8$ & $23.9 \pm 0.4$ & $5.5 \pm 0.1$ & - & $27.5 \pm 1.2$ \\
\hline & 4 & $\gamma$ & $42.3 \pm 0.3$ & $48.7 \pm 0.4$ & $8.2 \pm 0.1$ & $0.8 \pm 0.1$ & - \\
\hline \multirow{4}{*}{$47 \mathrm{Al}$} & 1 & $(\mathrm{Ti}, \mathrm{Nb})_{2} \mathrm{AlC}$ & $42.2 \pm 1.2$ & $25.2 \pm 1.3$ & $6.0 \pm 0.4$ & - & $26.5 \pm 1.1$ \\
\hline & 2 & $(\mathrm{Ti}, \mathrm{Nb}) \mathrm{C}$ & $48.0 \pm 2.3$ & $0.5 \pm 0.1$ & $4.7 \pm 1.1$ & - & $46.8 \pm 1.1$ \\
\hline & 3 & $\gamma+\alpha_{2}$ & $42.3 \pm 0.5$ & $48.5 \pm 0.5$ & $8.4 \pm 0.2$ & $0.8 \pm 0.1$ & - \\
\hline & 4 & $\gamma$ & $40.0 \pm 1.5$ & $52.7 \pm 2.6$ & $6.5 \pm 1.0$ & $0.7 \pm 0.1$ & - \\
\hline \multirow{2}{*}{ 47Al-HT } & 1 & $(\mathrm{Ti}, \mathrm{Nb})_{2} \mathrm{AlC}$ & $43.2 \pm 1.6$ & $25.9 \pm 1.4$ & $5.7 \pm 0.1$ & - & $25.0 \pm 0.2$ \\
\hline & 4 & $\gamma$ & $41.6 \pm 0.2$ & $50.8 \pm 0.5$ & $6.7 \pm 0.2$ & $0.9 \pm 0.2$ & - \\
\hline
\end{tabular}



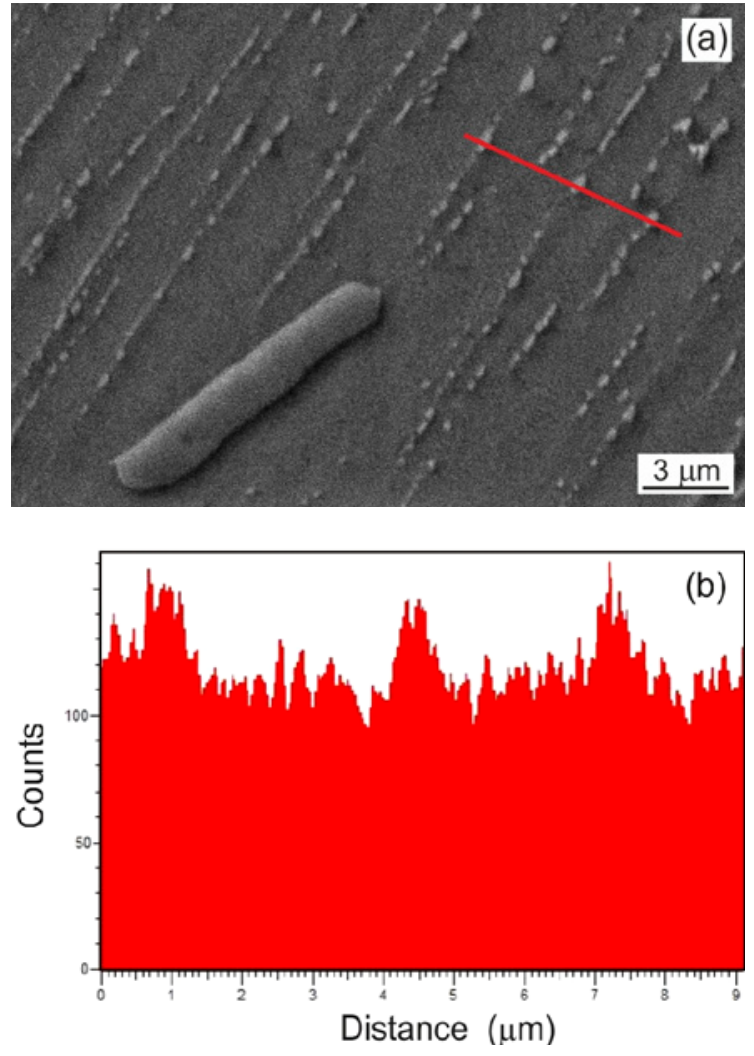

Fig. 4. (a) SEM micrograph of fine secondary carbide precipitates in the as-cast $45 \mathrm{Al}$ composite and position of EDS line analysis; (b) EDS line analysis of carbon through fine carbide particles.

ascribed by Fang et al. [35] to preferential segregation of $\mathrm{Nb}$ into the matrix. In all primary carbide particles including their cores, the Mo content was under detectable limit of the applied EDS analysis indicating that Mo is either not soluble or its solubility is very low in the MAX-phase.

The Al content has no significant effect on the volume fraction of the primary carbides in the as-cast composites, and all measured deviations fall within the experimental error of the measurements, as shown in Fig. 3. The average volume fraction of carbide particles is measured to be $(13.6 \pm 0.3)$ vol. $\%$, and the volume fraction of $(\mathrm{Ti}, \mathrm{Nb}) \mathrm{C}$ regions formed within the primary particles represents $(1.4 \pm 0.2)$ vol.\%. The increasing $\mathrm{Al}$ content from 38 to 47 at. $\%$ leads to a decrease in the volume fraction of $\beta / \mathrm{B} 2$-phase and an increase in volume fraction of lamellar $\alpha_{2}+\gamma$ and single $\gamma$-phase regions, as seen in Fig. 3a. However, the lamellar $\alpha_{2}+\gamma$ regions of the as-cast $45 \mathrm{Al}$ and $47 \mathrm{Al}$ composites are not stable during cooling, and occasionally, the precipitation of fine secondary carbide particles is observed within the partially decomposed $\alpha_{2}$ lamellae, as shown in Fig. 4.

Figure 5 shows the effect of $\mathrm{Al}$ content on the mean length of major axis $L_{\mathrm{maj}}$, mean length of minor
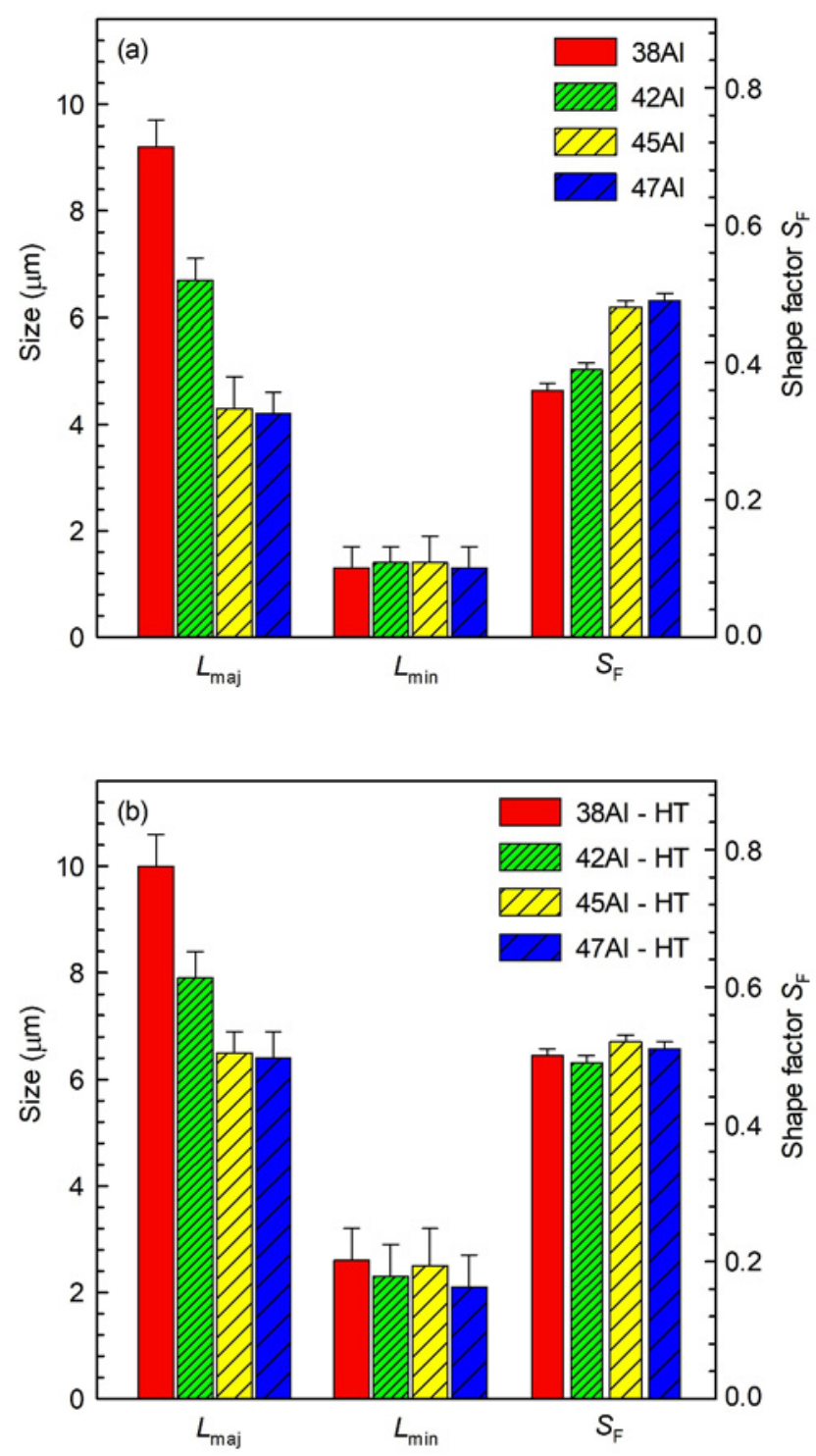

Fig. 5. Length of major axis $L_{\text {maj }}$, length of minor axis $L_{\mathrm{min}}$, and shape factor $S_{\mathrm{F}}$ of the primary carbide particles in (a) as-cast and (b) heat-treated composites. The Al content in the composites is indicated in the figure.

axis $L_{\text {min, }}$ and mean shape factor $S_{\mathrm{F}}$ of the primary $(\mathrm{Ti}, \mathrm{Nb})_{2} \mathrm{AlC}$ particles. The shape factor is calculated according to a relationship $S_{\mathrm{F}}=4 \pi A / P^{2}$, where $A$ is the area, and $P$ is the perimeter of the carbide particles. It should be noted that the mean length and mean shape factor of the carbide particles are determined from log-normal distribution function using statistical data (more than 2000 measured particles in each composite). The shape factor of the primary carbide particles increases from 0.36 to 0.50 , and their size characterised by the length of major and minor axis decreases with increasing $\mathrm{Al}$ content in the composites, as seen in Fig. 5a. 

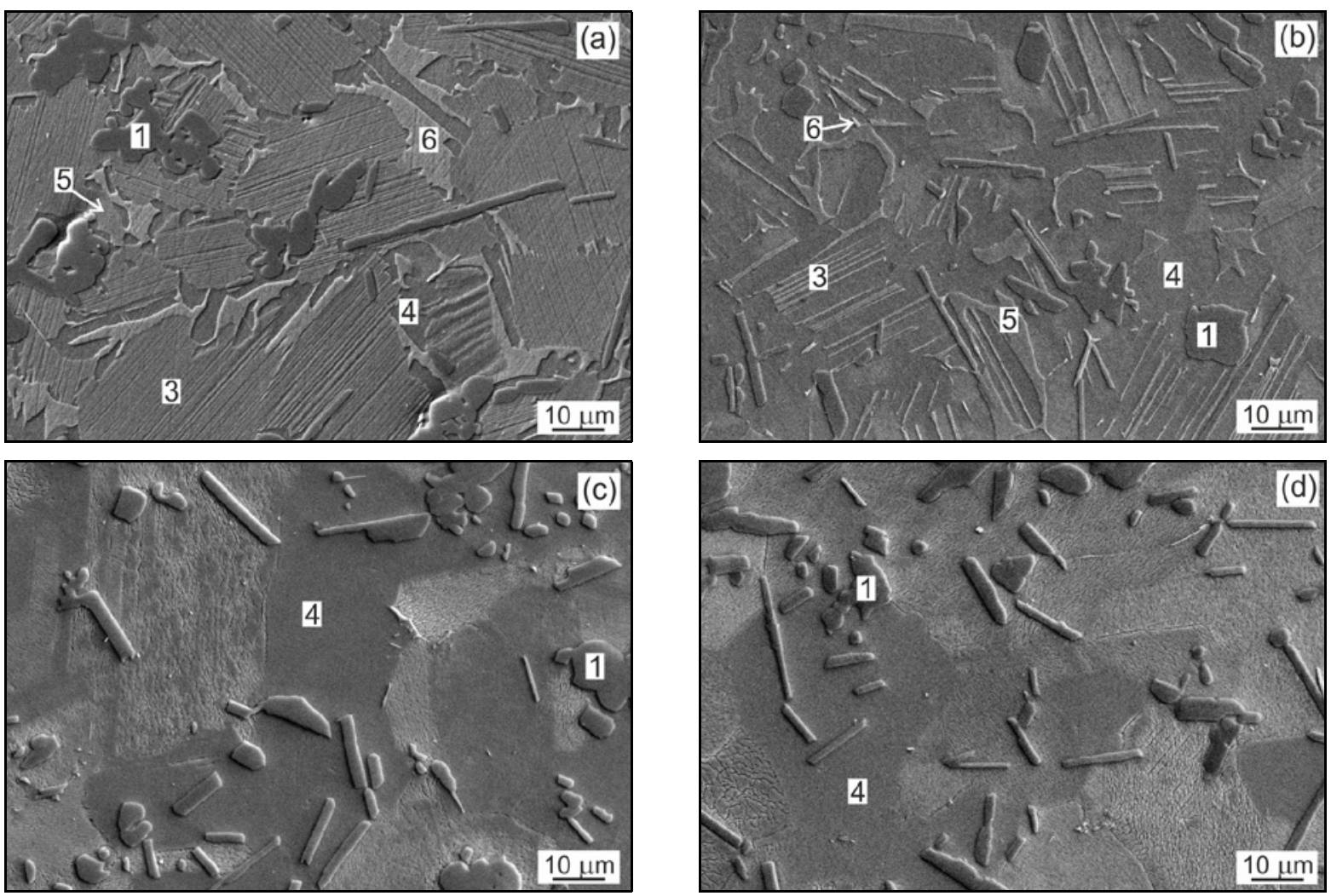

Fig. 6. SEM micrographs showing microstructure of the heat-treated composites: (a) 38Al-HT, (b) 42Al-HT, (c) 45Al-HT, and (d) 47Al-HT. The chemical compositions of analysed regions marked in the figures are summarised in Table 2.

\subsubsection{The microstructure of heat-treated composites}

The solution annealing of the studied composites at $1420^{\circ} \mathrm{C}$ and their consecutive cooling to room temperature induce phase transformations in the metastable intermetallic matrices and primary carbide particles, as shown in Fig. 6. Table 2 summarises the measured chemical composition of the coexisting phases, including primary carbide particles. The matrix of the heat-treated $38 \mathrm{Al}$ composite (38Al-HT) consists of lamellar $\alpha_{2}+\gamma$ grains with $\beta / \mathrm{B} 2-$ and $\gamma$-phase regions formed along the lamellar grain boundaries, as seen in Fig. 6a. The volume fraction of $\beta / \mathrm{B} 2$-phase decreases to $11 \mathrm{vol} \%$, which is less than half of the volume fraction of the $\beta / \mathrm{B} 2$-phase in the ascast sample, as seen in Figs. $3 \mathrm{a}$ and $3 \mathrm{~b}$. The matrix of the heat-treated $42 \mathrm{Al}$ composite ( $42 \mathrm{Al}-\mathrm{HT})$ is formed predominantly by the $\gamma$-phase, $\alpha_{2}$-phase in the form of thick lamellae or small irregular regions, and a small amount of $\beta / \mathrm{B} 2$ particles, as shown in Fig. 6b. The matrices of the heat-treated $45 \mathrm{Al}$ and $47 \mathrm{Al}$ composites (45Al-HT and 47Al-HT) are composed of single $\gamma$ grains, as shown in Figs. 6c,d. The residual fine $\beta / \mathrm{B} 2$ particles remain in the matrix of the heat-treated $45 \mathrm{Al}$ and $47 \mathrm{Al}$ composites, especially due to their stabilisation by Mo (Table 2).

Despite the high solution annealing temperature, the studied composites are not predisposed to undesirable grain growth, which usually accompanies solution annealing of TiAl-based alloys in $\alpha$-phase field [9]. Due to the presence of primary carbide particles, both the lamellar and $\gamma$ grains in the matrices of the heattreated composites with different $\mathrm{Al}$ content remain relatively small, and their average grain size ranges from 30 to $50 \mu \mathrm{m}$.

During the solution annealing, the $(\mathrm{Ti}, \mathrm{Nb}) \mathrm{C}$ regions in cores of the coarse irregular shaped carbide particles transform to $(\mathrm{Ti}, \mathrm{Nb})_{2} \mathrm{AlC}$-phase. This transformation is accompanied by a variation in particle morphology and an increase of the shape factor from 0.36-0.39 measured in the as-cast composites up to $0.47-0.50$ in the heat-treated $38 \mathrm{Al}$ and $42 \mathrm{Al}$ ones, as shown in Fig. 6b. However, an increase in the volume fraction of the primary carbide particles in the heat-treated composites compared to that of the ascast ones are not explicit because all measured differences fall within the experimental errors of the measurements, as seen in Figs. 3a,b. Figure 5b indicates that the mean length of the major axis and minor axis of the primary carbides increases in the heat-treated composites compared to those measured in the as-cast ones. The increase in the measured size of the primary carbide particles can be explained by the elimination of narrow boundaries between individual particles during the heat-treatment, especially in the coarse irregu- 

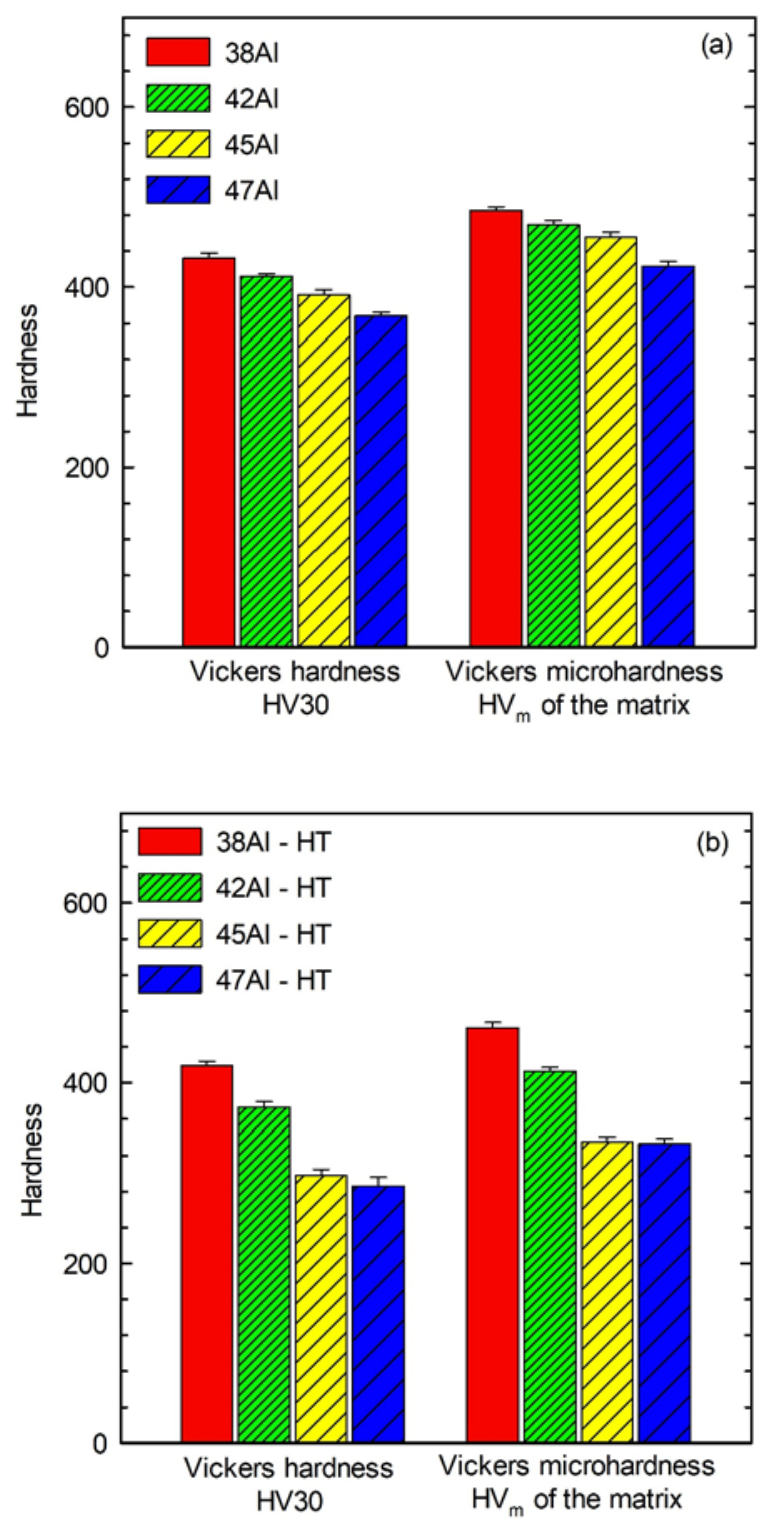

Fig. 7. The evolution of Vickers hardness HV 30 and microhardness $\mathrm{HV}_{\mathrm{m}}$ of the matrix with the $\mathrm{Al}$ content: (a) as-cast composites; (b) heat-treated composites. The $\mathrm{Al}$ content in the composites is indicated in the figure.

lar shaped carbides. However, this increase in the size is connected with a negligible change in a volume fraction of the primary carbide particles.

\subsection{Hardness and microhardness}

Figure 7 shows the effect of $\mathrm{Al}$ content on Vickers hardness HV30 and matrix microhardness $\mathrm{HV}_{\mathrm{m}}$ of the as-cast and heat-treated composites.

The decrease of the Vickers hardness HV30 with the increasing $\mathrm{Al}$ content (Fig. 7a) can be related mainly to a decrease of the matrix microhardness.
The phase transformations lead to a decrease of matrix microhardness $\mathrm{HV}_{\mathrm{m}}$ and Vickers hardness HV30 of the heat-treated composites in comparison with those of the as-cast ones. The measurements of the indentation nanohardness $\mathrm{H}_{\mathrm{IT}}$ indicate that the $\gamma$-phase is the softest phase in the composite with $H_{\mathrm{IT}}=(6.8 \pm 0.4) \mathrm{GPa}$, and $\beta / \mathrm{B} 2$-phase with $H_{\mathrm{IT}}=$ $(8.2 \pm 0.7) \mathrm{GPa}$ is the hardest phase in the intermetallic matrices, what is in a good agreement with the results reported in recent works $[36,37]$. The high amount of the lamellar $\alpha_{2}+\gamma$ colonies and $\beta / \mathrm{B} 2-$ -phase regions in the $38 \mathrm{Al}-\mathrm{HT}$ composite result in a high Vickers hardness value of about 400 HV30. The phase transformations in the multiphase matrix of $45 \mathrm{Al}$ and $47 \mathrm{Al}$ composites to the soft $\gamma$-phase during the heat-treatment lead to a decrease of the Vickers hardness to about 300 HV30. Besides the softening of the matrix, the phase changes in the primary carbide particles contribute to a decrease in the hardness of the heat-treated composites. The measurements of the nanohardness of primary carbide particles indicate that the nanohardness of the $(\mathrm{Ti}, \mathrm{Nb}) \mathrm{C}$-phase reaches an average value of $(23.7 \pm 0.8) \mathrm{GPa}$ in the as-cast composites. On the other hand, the nanohardness of $(\mathrm{Ti}, \mathrm{Nb})_{2} \mathrm{AlC}$ phase is measured to be only $(10.3 \pm 0.5) \mathrm{GPa}$ in both the as-cast and heat-treated composites. Hence, the transformation of $(\mathrm{Ti}, \mathrm{Nb}) \mathrm{C}$ to $(\mathrm{Ti}, \mathrm{Nb})_{2} \mathrm{AlC}$-phase leads to a softening of the primary carbide particles during the heat treatment.

\section{Discussion}

Since phase diagrams describing phase transformations in the studied composites with chemical composition close to 8 at. $\% \mathrm{Nb}, 1$ at.\% Mo, and 3.6 at. $\%$ $\mathrm{C}$ are not available, the solidification path and phase equilibria can be estimated based on phase diagrams reported for Nb-, Nb-Mo-, and C-doped TiAl-based alloys [38-42]. According to the ternary Ti-Al-C-phase diagrams [42], the cubic $\mathrm{TiC}_{1-x}$-phase is formed as a primary solidification phase in the melt at high temperatures. During solidification, $\mathrm{TiC}_{1-x}$ transforms into hexagonal $\mathrm{H}-\mathrm{Ti}_{2} \mathrm{AlC}$-phase. Based on the microstructural observations of the studied as-cast and heat-treated composites, the casting temperature of $1650^{\circ} \mathrm{C}$ applied in the present work corresponds to two-phase equilibria $\mathrm{L}+(\mathrm{Ti}, \mathrm{Nb}) \mathrm{C}$ and during solidification a new equilibrium $\mathrm{L}+(\mathrm{Ti}, \mathrm{Nb})_{2} \mathrm{AlC}$ is created. Differences in the solubility of $\mathrm{C}$ in the particular phases and different sizes of $\mathrm{L}+(\mathrm{Ti}, \mathrm{Nb})_{2} \mathrm{AlC}$ or $\mathrm{L}+(\mathrm{Ti}, \mathrm{Nb})_{2} \mathrm{AlC}+\beta$ phase fields in the studied composites affect the formation and growth of primary $(\mathrm{Ti}, \mathrm{Nb})_{2} \mathrm{AlC}$ particles during casting. The shorter the $\mathrm{L}+(\mathrm{Ti}, \mathrm{Nb})_{2} \mathrm{AlC}$ or $\mathrm{L}+(\mathrm{Ti}, \mathrm{Nb})_{2} \mathrm{AlC}+\beta$ phase fields and higher the cooling rate, the smaller $(\mathrm{Ti}, \mathrm{Nb})_{2} \mathrm{AlC}$ particles are formed. In the case of the $38 \mathrm{Al}$ composite, 
$\mathrm{L}+(\mathrm{Ti}, \mathrm{Nb})_{2} \mathrm{AlC}$ or $\mathrm{L}+(\mathrm{Ti}, \mathrm{Nb})_{2} \mathrm{AlC}+\beta$ fields are supposed to be the widest of all four investigated composites, which leads to the formation of large amount of thin long plate-like particles together with coarse clustering carbides during solidification. On the other hand, the solidification of the $45 \mathrm{Al}$ and $47 \mathrm{Al}$ composites includes narrow $\mathrm{L}+(\mathrm{Ti}, \mathrm{Nb})_{2} \mathrm{AlC}$ phase field and solidification accompanied with a peritectic type of reaction/transformation, which leads to the formation of significantly smaller primary carbide particles, as seen in Fig. 5.

The formation of the secondary carbide particles, their size, and morphology is closely related to the chemical and phase composition of the matrix, especially to the solubility of $\mathrm{C}$ in the particular phases. The interstitial atoms of $\mathrm{C}$ exhibit various solubility limits in the coexisting phases of TiAl-based alloys, and moreover, their solubility is also affected by the presence of additional alloying elements such as $\mathrm{Nb}$, Mo or $\mathrm{Cr}[36,43,44]$. In general, the solubility of $\mathrm{C}$ in $\beta / \mathrm{B} 2$-phase is negligible [45]. The maximum solubility of $\mathrm{C}$ in $\alpha_{2}$-phase was measured to be $\sim 1.0-1.5$ at. $\%$ $[36,43]$. The maximum solubility of $\mathrm{C}$ in $\gamma$-phase of Nb-doped TiAl-based alloys was estimated to be much smaller, only $0.25-0.4$ at.\% [43, 44]. In Nb-doped TiAlbased alloys with a higher content of $\mathrm{Al}$ than $\mathrm{Ti}$, the solubility limit of $\mathrm{C}$ in $\gamma$-phase is even smaller and was measured to be below 0.1 at.\% [46]. Due to the lower solubility limit of $\mathrm{C}$ in the $\gamma$-phase in comparison with that in the $\alpha_{2}$-phase, the secondary carbide particles precipitate alongside $\alpha_{2} / \gamma$ lamellar interfaces and $\gamma / \gamma$ grain boundaries during cooling in the moulds (see Fig. 4) or consequent heat treatment [47, 48].

The decrease of matrix microhardness and Vickers hardness of the $45 \mathrm{Al}$ and $47 \mathrm{Al}$ composites and formation of a single $\gamma$-phase matrix are expected to improve room-temperature ductility of TiAl-based matrix composites reinforced with carbide particles $[6-$ 8]. Slip systems in $\alpha_{2}$-phase with hcp structure are limited compared with the slip systems of $\gamma$-phase. The plastic deformation occurs preferentially in the $\gamma$-phase but reinforcing $(\mathrm{Ti}, \mathrm{Nb})_{2} \mathrm{AlC}$ particles hinder the dislocation motion, which results in an increase of yield strength and creep resistance [47, 48]. However, such ductilisation of the composites through the formation of the $\gamma$ matrix is at the expense of a decrease of high-temperature creep resistance characterised by higher minimum creep rates [48] and shorter creep life assuming Monkmann-Grant empirical formula [49] compared to composites with fully lamellar matrix [13].

\section{Conclusions}

The effect of $\mathrm{Al}$ content ranging from 38 to 47 at.\% on the microstructure of the as-cast and heat-treated
Ti- $x$ Al-8Nb-3.6C-0.8Mo (at.\%) composites reinforced with carbide particles was studied. The following conclusions are reached:

1. The microstructure of the as-cast composites is formed by multiphase intermetallic matrices reinforced with relatively uniformly distributed primary carbide particles. The matrices of the composites consist of $\alpha_{2^{-}}, \gamma-$, and $\beta /$ B2-phases. The primary carbide particles are composed of $(\mathrm{Ti}, \mathrm{Nb})_{2} \mathrm{AlC}$-phase and a small amount of $(\mathrm{Ti}, \mathrm{Nb}) \mathrm{C}$-phase preserved in the cores of some coarse irregular shaped carbides.

2. The increasing $\mathrm{Al}$ content from 38 to 47 at. $\%$ leads to a decrease in the volume fraction of $\beta / \mathrm{B} 2$ -phase and an increase in the volume fraction of the lamellar $\alpha_{2}+\gamma$ and single $\gamma$-phase regions in the ascast composites. The increasing $\mathrm{Al}$ content has no significant effect on the volume fraction but increases shape factor, and decreases the mean size of the primary carbide particles.

3. In the heat-treated composites, the intermetallic matrices change from multiphase composed of lamellar $\alpha_{2}+\gamma$ grains with $\beta /$ B2- and $\gamma$-phase regions formed along the lamellar grain boundaries, through nearly lamellar to single $\gamma$-phase with increasing Al content. The $(\mathrm{Ti}, \mathrm{Nb}) \mathrm{C}$ regions in the core of some carbide particles transform to $(\mathrm{Ti}, \mathrm{Nb})_{2} \mathrm{AlC}$-phase during the heat treatment. The heat treatment increases the mean size of the primary carbide particles but has no significant effect on their volume fraction.

4. The Vickers hardness and matrix microhardness decrease with the increasing $\mathrm{Al}$ content in both the ascast and heat-treated composites. The heat treatment leads to a softening of the composites. The decrease of the Vickers hardness and microhardness with increasing $\mathrm{Al}$ content is more pronounced in the heat-treated composites.

\section{Acknowledgements}

This work was financially supported by the Slovak Research and Development Agency under the contract APVV-15-0660. The experimental work was carried out thanks to the infrastructure supported by the Research and Development Operational Program funded by the European Regional Development Fund in the frame of the projects: Center for Applied Research of New Materials and Technology Transfer (ITMS 26240220088) and Center of Applied Research ALLEGRO (ITMS 26220220198).

\section{References}

[1] Kim, Y. W.: JOM, 70, 2018, p. 553. doi:10.1007/s11837-018-2747-x

[2] Bewlay, B. P., Nag, S., Suzuki, A., Weimer, M. J.: Mater. High Temp., 33, 2016, p. 549. doi:10.1080/09603409.2016.1183068 
[3] Tetsui, T., Kobayashi, T., Ueno, T., Harada, H.: Intermetallics, 31, 2012, p. 274. doi:10.1016/i.intermet.2012.07.019

[4] Fu, P. X., Kang, X. H., Ma, Y. C., Liu, K., Li, D. Z., Li, Y. Y.: Intermetallics, 16, 2008, p. 130. doi:10.1016/j.intermet.2007.08.007

[5] Bünck, M., Stoyanov, J., Schievenbusch, T., Michels, H., Gußfeld, A.: JOM, 69, 2017, p. 2565. doi:10.1007/s11837-017-2534-0

[6] Kim, Y. W.: Intermetallics, 6, 1998, p. 623. doi:10.1016/S0966-9795(98)00037-5

[7] Appel, F., Wagner, R.: Mater. Sci. Eng. R, 22, 1998, p. 187. doi:10.1016/S0927-796X(97)00018-1

[8] Dimiduk, D. M., Martin, P. L., Kim, Y.: Mater. Sci. Eng. A, 243, 1998, p. 66. doi:10.1016/S0921-5093(97)00780-6

[9] Kamyshnykova, K., Lapin, J.: Kovove Mater., 56, 2018, p. 277. doi:10.4149/km_2018_5_277

[10] Kim, Y. W., Kim, S.L.: Intermetallics, 53, 2014, p. 92. doi:10.1016/i.intermet.2014.04.006

[11] Appel, F. Clemens, H., Fischer, F. D.: Prog. Mater. Sci., 81, 2016, p. 55. doi:10.1016/i.pmatsci.2016.01.001

[12] Lapin, J., Klimová, A., Gabalcová, Z., Pelachová, T., Bajana, O., Stamborská, M.: Mater. Design, 133, 2017, p. 404. doi:10.1016/i.matdes.2017.08.012

[13] Lapin, J., Kamyshnykova, K.: Intermetallics, 98, 2018, p. 34. doi:10.1016/j.intermet.2018.04.012

[14] Song, X. J., Cui, H. Z., Hou, N., Wei, N., Han, Y., Tian, J., Song, Q.: Ceram. Int., 42, 2016, p. 13586. doi:10.1016/j.ceramint.2016.05.152

[15] Chen, R., Fang, H., Chen, X., Su, Y., Ding, H., Guo, J., Fu, H.: Intermetallics, 81, 2017, p. 9. doi:10.1016/i.intermet.2017.02.025

[16] Stamborská, M., Lapin, J., Bajana, O.: Kovove Mater., 56, 2018, p. 349. doi:10.4149/km_2018_6_349

[17] Cegan, T., Szurman, I.: Kovove Mater., 55, 2018, p. 421. doi:10.4149/km_2017_6_421

[18] Lapin, J., Stamborská, M., Pelachová, T., Bajana, O.: Mater. Sci. Eng. A, 721, 2018, p. 1. doi:10.1016/j.msea.2018.02.077

[19] Gabrisch, H., Stark, A., Schimansky, F. P., Wang, L., Schell, N., Lorenz, U., Pyczak, F.: Intermetallics, 33, 2013, p. 44. doi:10.1016/j.intermet.2012.09.023

[20] Fang, H., Chen, R., Yang, Y., Su, Y., Ding, H., Guo, J., Fu, H.: Mater. Design, 156, 2018, p. 300. doi:10.1016/j.matdes.2018.06.048

[21] Yang, C., Wang, F., Ai, T., Zhu, J.: Ceram. Int., 40, 2014, p. 8165. doi:10.1016/j.ceramint.2014.01.012

[22] Yang, F., Kong, F. T., Chen, Y. Y., Xiao, S. L.: J. Alloys Compd., 496, 2010, p. 462. doi:10.1016/j.jallcom.2010.02.077

[23] Ramkumar, J., Malhotra, S. K., Krishnamurthy, R., Mabuchi, H., Demizu, K., Kakitsuji, A., Tsuda, H., Matsui, T., Morii, K.: Mater. Trans., 44, 2003, p. 1861. doi:10.2320/matertrans.44.1861

[24] Yeh, C. L., Shen, Y.G.: Intermetallics, 17, 2009, p. 169. doi:10.1016/j.intermet.2008.10.014

[25] Song, X., Cui, H., Han, Y., Hou, N., Wei, N., Ding, L., Song, Q.: Mater. Sci. Eng. A, 684, 2017, p. 406. doi:10.1016/i.msea.2016.12.069

[26] Ramaseshan, R., Kakitsuji, A., Seshadri, S. K., Nair, N. G., Mabuchi, H., Tsuda, H., Matsui, T., Morii, K.: Intermetallics, 7, 1999, p. 571 . doi:10.1016/S0966-9795(98)00069-7
[27] Lapin, J., Gabalcová, Z., Pelachová, T.: Intermetallics, 19, 2011, p. 396. doi:10.1016/j.intermet.2010.11.007

[28] Cui, R. J., Tang, X. X., Gao, M., Zhang, H., Gong, S. K.: Mater. Sci. Eng. A, 541, 2012, p. 14. doi:10.1016/j.msea.2012.01.099

[29] Zhang, H., Ding, H., Wang, Q., Chen, R., Guo, J.: Vacuum, 148, 2018, p. 206. doi:10.1016/i.vacuum.2017.11.032

[30] Kuang, J. P., Harding, R. A., Campbell, J.: Int. J. Cast Met. Res., 13, 2001, p. 277. doi:10.1080/13640461.2001.11819409

[31] Kamyshnykova, K., Lapin, J.: Vacuum, 154, 2018, p. 218. doi:10.1016/j.vacuum.2018.05.017

[32] Cegan, T., Szurman, I., Kursa, M., Holešinský, J., Vontorová, J.: Kovove Mater., 53, 2015, p. 69. doi:10.4149/km_2015_2_69

[33] Lapin, J., Klimová, A.: Vacuum, 169, 2019, p. 108930. doi:10.1016/j.vacuum.2019.108930

[34] Kainuma, R., Fujita, Y., Mitsui, H., Ohnuma, I., Ishida, K.: Intermetallics, 8, 2000, p. 855. doi:10.1016/S0966-9795(00)00015-7

[35] Fang, H., Chen, R., Gong, X., Su, Y., Ding, J., Guo, H., Fu, H.: Adv. Eng. Mater., 20, 2018, p. 1. doi:10.1002/adem.201701112

[36] Klein, T., Schachermayer, M., Mendez-Martin, F., Schöberl, T., Rashkova B., Clemens, H., Mayer, S.: Acta Mater., 94, 2015, p. 205. doi:10.1016/j.actamat.2015.04.055

[37] Schloffer, M., Iqbal, F., Gabrisch, H., Schwaighofer, E., Schimansky, F. P., Mayer, S., Stark, A., Lippmann, T., Göken, M., Pyczak, F., Clemens, H.: Intermetallics, 22, 2012, p. 231. doi:10.1016/j.intermet.2011.11.015

[38] Chladil, H. F., Clemens, H., Leitner, H., Bartels, A., Gerling, R., Schimansky, F. P., Kremmer, S.: Intermetallics, 14, 2006, p. 1194. doi:10.1016/i.intermet.2005.11.016

[39] Chen, G. L., Xu, X. J., Teng, Z. K., Wang, Y. L., Lin, J. P.: Intermetallics, 15, 2007, p. 625. doi:10.1016/j.intermet.2006.10.003

[40] Bondar, A. A., Witusiewicz, V. T., Hecht, U., Remez, M. V., Voblikov, V. M., Tsyganenko, N. I., Yevich, Y. I., Podrezov, Y. M.: Powder Metall. Met. Ceram., 50, 2011, p. 397. doi:10.1007/s11106-011-9345-6

[41] Schwaighofer, E., Clemens, H., Mayer, S., Lindemann, J., Klose, J., Smarsly, W., Güther, V.: Intermetallics, 44, 2014, p. 128. doi:10.1016/j.intermet.2013.09.010

[42] Witusiewicz, V. T., Hallstedt, B., Bondar, A. A., Hecht, U., Sleptsov, S. V., Velikanova, T. Y.: J. Alloys Compd., 623, 2015, p. 480. doi:10.1016/j.jallcom.2014.10.119

[43] Scheu, C., Stergar, E., Schober, M., Cha, L., Clemens, H., Bartels, A., Schimansky, F. P., Cerezo, A.: Acta Mater., 57, 2009, p. 1504. doi:10.1016/j.actamat.2008.11.037

[44] Schwaighofer, E., Rashkova, B., Clemens, H., Stark, A., Mayer, S.: Intermetallics, 46, 2014, p. 173. doi:10.1016/j.intermet.2013.11.011

[45] Perdrix, F., Trichet, M. F., Bonnentien, J. L., Cornet, M., Bigot, J.: Intermetallics, 9, 2001, p. 807. doi:10.1016/S0966-9795(01)00066-8

[46] Wu, Z., Hu, R., Zhang, T., Zhang, F., Kou, H., Li, J.: Mater. Charact., 124, 2017, p. 1. doi:10.1016/j.matchar.2016.12.008 
[47] Lapin, J., Štamborská, M., Kamyshnykova, K., Pelachová, T., Klimová, A., Bajana, O.: Intermetallics, 105, 2019, p. 113. doi:10.1016/j.intermet.2018.11.007

[48] Lapin, J., Pelachová, T., Bajana, O.: J. Alloys Compd., 797, 2019, p. 754.

doi:10.1016/J.JALLCOM.2019.05.136
[49] Sklenička, V., Kuchařová, K., Král, P., Kvapilová, M., Dvořák, J.: Kovove Mater., 55, 2017, p. 69. doi:10.4149/km_2017_2_69 